\title{
An overview of non-destructive approaches for quality determination in pineapples
}

\author{
Maimunah Mohd Alia* ${ }^{*}$ Norhashila Hashima,c, Samsuzana Abd Aziza,c, Ola Lasekan ${ }^{\mathrm{b}}$
}

a Department of Biological and Agricultural Engineering, Faculty of Engineering, Universiti Putra Malaysia, 43400 Serdang, Selangor, Malaysia ${ }^{b}$ Department of Food Technology, Faculty of Food Science and Technology, Universiti Putra Malaysia, 43400 UPM Serdang, Selangor, Malaysia cSMART Farming Technology Research Centre, Faculty of Engineering, Universiti Putra Malaysia, 43400 UPM Serdang, Selangor, Malaysia

\section{ARTICLE HISTORY}

Received: 26 March 2020

Received in revised form: 29 April

2020

Accepted: 1 May 2020

Available Online: 2 May 2020

\section{Keywords}

Computer vision

Non-destructive

Pineapple

Quality evaluation

Spectroscopy

\section{Abstract}

Pineapple is one of the healthful and popular tropical fruits in the world. The quality determination of pineapples was mostly evaluated by human inspection which is inconsistent and subjective. The increasing demand for pineapples creates more opportunities for the advancement of rapid and non-destructive approaches to seek quality evaluation of the fruit. This review gives an overview of the non-destructive approaches on the quality determination of pineapples including computer vision, imaging-based approaches, spectroscopy-based approaches, acoustic impulse, and electronic nose. The advance of non-destructive techniques to evaluate the quality of pineapple can produce better yield and improve postharvest handling. This paper also highlighted the recent works on the quality determination of pineapple fruit using non-destructive approaches along with the abundant information that can be explored for real-time purposes. This information is expected to be useful not only for pineapples growers/industries but also for other agro-food commodities.

\section{Introduction}

Pineapple is one of the world's most popular tropical fruits within international trade. The quality determination of the fruit is a major aspect of the pineapple industry due to huge demand in the competitive markets (Bugaud \& Alter, 2016; Sung et al., 2019). The interest in pineapple quality evaluation is governed by the need to offer to the consumer with high-quality fruit. For instance, the chemical attributes of pineapple need to be evaluated by the analytical methods which are laborious and time-consuming to determine the internal quality of the fruit. For this reason, there is a need to provide a rapid and reliable method to replace the conventional method due to the high production of pineapples to be analyzed in a short time. Various quality and chemical attributes can be determined including color evaluation, firmness, total acidity, soluble solids content (SSC), pH, chlorophyll concentration, acids, and oils (Li et al., 2018). For pineapple, the fruit is graded manually by human inspection by the tapping sound around the middle of the fruit (Sornsrivichai et al., 2000).

Non-destructive approaches have been conducted to determine the pineapple quality over the past few years (Chia et al., 2012; Di Egidio et al., 2009; Donis-González et al., 2014; Khatiwada et al., 2016; Srivichien et al., 2015; Torri et al., 2010). Recently, the pineapple industry has a growing need for developing robust and efficient methods to be used in the quality determination of the fruit. Numerous fast and nondestructive methods have been used in tandem with the quality evaluation of pineapples. These non-destructive methods include computer vision system (Angel et al., 2015), imagingbased approaches (Barral et al., 2019), spectroscopy-based approaches (Khatiwada et al., 2016), acoustic impulse (Valente et al., 2001), and electronic nose (Kalpana \& Lakshmi Baghyam, 2019).

The applications of non-destructive methods for quality determination of pineapples involve predicting the chemical attributes and physical characteristics, disease and defect detection, as well as electronic-based classification (Shamsudin *Corresponding author email: maimunah_mohdali@ymail.com et al., 2007; Siti Rashima et al., 2019; Yee et al., 2011). Despite having a significant number of research studies concerning the application of rapid determination of quality changes of pineapples, no study has been done to technically present the summarization of different non-destructive approaches. The recent studies on the quality evaluation of pineapple using the potential of available non-destructive approaches concerning the maturity, biochemical, and chemical attributes are reported with the continuous technical innovations executing in a lowcost and rapid way for real-time detection of the fruit. Despite there have been several new developments, updated progress on non-destructive techniques was provided for the quality evaluation of pineapple. Hence, this review aims to provide the future possibility to adopt these non-destructive approaches which have demonstrated reliable success for quality evaluation of pineapples.

\section{Non-destructive approaches for quality evaluation of pineapple}

The rapid development of non-destructive technologies for quality evaluation of pineapple is the ultimate goal of the fundamental studies in the pineapple industry. The evaluation of pineapple quality is a critical factor in monitoring the quality and shelf life of the fruit. To date, the potential of using nondestructive techniques for quality evaluation of pineapple has been expanded tremendously. These non-destructive technologies specifically for detection of pineapple quality includes computer vision systems, imaging-based techniques, spectroscopy-based techniques, and other relevant nondestructive techniques. Table 1 shows the applications of nondestructive technologies for quality evaluation of pineapple.

\subsection{Computer vision approaches}

Computer vision systems have been widely used for quality and safety inspection of fruits and vegetables

(C) 2020 The Authors. Published by SixScientia Resources 
Table 1. The applications of non-destructive technologies for quality evaluation of pineapple.

\begin{tabular}{|c|c|c|c|}
\hline Application & Quality parameters & Data analysis & References \\
\hline Computer vision & Fruit classification & Image processing & (Bin Li, Wang, \& Li, 2010) \\
\hline Electronic nose & Fruit freshness & PCA, cluster analysis & (Torri et al., 2010) \\
\hline Computer vision & Fruit classification & Image processing & (Mohammad et al., 2012) \\
\hline $\begin{array}{l}\text { Vis and shortwave NIR } \\
\text { spectroscopy }\end{array}$ & Soluble solids content & ANN & (Chia et al., 2012) \\
\hline Biosensor & Maturity & DNA detection & (Chaumpluk et al., 2012) \\
\hline Computer vision & Maturity & Fuzzy logic algorithm & (Abu Bakar et al., 2013) \\
\hline NIR spectroscopy & Internal browning & PLS-DA & $\begin{array}{l}\text { (Sukwanit \& Teerachaichayut, } \\
\text { 2013) }\end{array}$ \\
\hline Computer vision & Fruit grading & Hidden-Markov model & (Phoophuangpairoj \& Srikun, 2014) \\
\hline NIR spectroscopy & Soluble solids content & Multiple linear regression & (Rahim et al., 2014) \\
\hline Computed tomography imaging & Internal characterisation & ANOVA & (Donis-González et al., 2014) \\
\hline Computer vision & Fruit grading & Texture analysis & (Dittakan et al., 2018) \\
\hline Visible-NIR spectroscopy & Nitrate level & PLS & (Srivichien et al., 2015) \\
\hline Computer vision & Maturity & $\begin{array}{l}\text { Modified basic sequential } \\
\text { algorithmic scheme algorithm }\end{array}$ & (Angel et al., 2015) \\
\hline Computer vision & Fruit grading & Fuzzy logic & (Suksawat \& Komkum, 2015) \\
\hline $\begin{array}{l}\text { Electrochemical impedance } \\
\text { spectroscopy }\end{array}$ & Fermentable sugar & PLS, PCA, ANN & (Conesa et al., 2015) \\
\hline NIR spectroscopy & Internal defect & PLS, LDA & (Khatiwada et al., 2016) \\
\hline Computer vision & Translucency assessment & Image processing & (Lima et al., 2016) \\
\hline $\begin{array}{l}\text { Electronic nose, electronic } \\
\text { tongue }\end{array}$ & Fruit classification & PCA & (Haddi et al., 2014) \\
\hline NIR light emitting diodes & Internal quality & Artificial neural network & (Jam \& Chia, 2017) \\
\hline Computer vision & Maturity & Image processing & (Nawawi \& Ismail, 2017) \\
\hline X-Ray tomography & Fruitlet core rot & ANOVA & (Barral et al., 2019) \\
\hline Electronic nose & Fruit classification & $\begin{array}{l}\text { K-nearest neighbour } \\
\text { algorithm }\end{array}$ & (Kalpana \& Baghyam, 2019) \\
\hline $\begin{array}{l}\text { Fourier transform infrared } \\
\text { spectroscopy }\end{array}$ & $\begin{array}{l}\text { Total phenolic content } \\
\text { and antioxidant capacity }\end{array}$ & PCA & (Santos et al., 2019) \\
\hline NIR spectroscopy & Total soluble solids & PCA, LDA & (Amuah et al., 2019) \\
\hline
\end{tabular}

ANOVA, analysis of variance; PLS-DA, Partial least squares-discriminant analysis; PLS, Partial least squares; ANN, artificial neural network; LDA, linear discriminant analysis; NIR, near-infrared; PCA, principal component analysis.

(Mohd Ali et al., 2017). It is recognized as the integration of optical sensing and computing processes in order to evaluate the datasets automatically (Brosnan \& Sun, 2004). Kaewapichai et al. (2007) developed pineapple scale models to determine automatic detection for maturity grading of the fruit. Based on the model, a modified algorithm was used to accurately fit the scale model using pineapple features including boundary, internal area, and petal scale. Li, Wang, \& Wang (2010) investigated the application of computer vision for developing pineapple harvesting robotic system under field condition. Several processing algorithms were established to extract the features from the pineapple datasets by means of fruit location and central coordinates. The findings successfully achieved fruit recognition rate with $90 \%$ when harvested during clear sky compared to cloudy days with the recognition rate of $60 \%$. Similarly, Li, Wang, \& Li (2010) reported the application of pineapple harvesting robot system using computer vision platform. The feature selections were extracted from the fruit area to compare the matching area with the real-time matching area by developing robust features algorithms.

In another approach, Mohammad et al. (2012) evaluated a computer vision system for automatic detection of pineapple maturity. The finding demonstrated a high classification rate of $94 \%$ using linear classification method, indicating the efficiency of maturity detection of pineapple. Abu Bakar et al. (2013) developed a fuzzy logic classification using computer vision in order to determine the ripeness of pineapple between unripe, ripe, and fully-ripe fruits. Based on the findings, the system successfully classified the fully-ripe fruits with $100 \%$ classification accuracy and $85 \%$ for ripe and unripe fruits, respectively. Phoophuangpairoj \& Srikun (2014) proposed a computerized system based on the physical and physicochemical properties of pineapple to determine the fruit grading. The fruit grading was evaluated using flicking sounds and signal processing with respect to the texture, total soluble solids, $\mathrm{pH}$, and water content of pineapple. It is noted that the feasibility of this technique to develop an automated grading system can efficiently determine the pineapple quality by means of non-destructive approach without destructing the fruit.

A computer vision system based on the pineapple grading was developed by Suksawat \& Komkum (2015) to classify the fruits into standard weight and sizes. The fuzzy system was established to distinguish the fruits with the average relative errors of $5.24 \%$ and $2.30 \%$ according to the respective standard weight and sizes, respectively. In a research study performed by Angel et al. (2015), an automated computer vision system for maturity grading of pineapple was developed. The modified basic sequential algorithmic scheme was used to evaluate the maturation state of the fruit. Based on the finding, it was revealed that the established algorithm efficiently classified the maturity of pineapple with the classification accuracy of $96 \%$. Lima et al. (2016) investigated the application of computer vision system for translucency evaluation coated with cassava starch. The results demonstrated that fruit translucency can be determined using the proposed system with the high correlation of 0.91 , signifying that the edible coatings did not affect the fruit quality for the quantification of translucent areas of pineapple. Nawawi \& Ismail (2017) also investigated the application of computer vision in order to classify the maturity of pineapple using ellipse hough transform algorithm. In a similar manner, Dittakan et al. (2018) classified two grades of pineapple according to the sweetness and juiciness using computer vision system. Using the texture analysis algorithm, the classification model successfully distinguished between the two pineapple grades with an accuracy of $97 \%$. 


\subsection{Imaging-based approaches}

Various applications in the imaging-based techniques are rapidly emerged in monitoring quality evaluation of pineapple. Sornsrivichai et al. (2000) investigated the X-ray computed tomography (CT) imaging to classify the pineapple grading. The intensity of X-ray CT images was correlated with the fruit maturity to identify internal defects of the pineapple flesh, signifying that the imaging approach is effective in the evaluation of the internal quality of the fruit during storage. In a similar study, Haff et al. (2006) discussed the application of Xray CT imaging for translucency evaluation of pineapple. Based on the finding, it was observed that the pineapple with no translucency was successfully classified up to $95 \%$ whereas the severe translucency was identified up to $86 \%$. In this study, it can be signified that X-ray CT imaging is a competent method for the determination of pineapple translucency with different translucency levels.

Donis-González et al. (2014) used an ultrafast X-ray CT imaging to determine the translucency disorder in pineapple in order to visualize the internal characteristics of the fruit. Figure 1 illustrates the different types of images obtained from X-ray CT imaging which comprised of the color raw images, crosssectional two-dimensional (2D) CT images, and threedimensional (3D) reconstruction of pineapple slices. The results demonstrated that the two-dimensional CT X-ray images can be used potentially for detection of internal attributes of pineapple at an early stage. In relation to studies on pineapple translucency, Khatiwada et al. (2016) also used CT X-ray imaging to access the visual inspection of internal tissue and defects of the fruit. In this research, partial least square regression and linear discriminant analysis (LDA) were used to develop the model based on the internal defects of pineapple. Barral et al. (2019) explored the potential applications of X-ray imaging and fluorescence imaging in order to identify the fruitlet infection of two different varieties of pineapples. The finding showed that fungi were identified in the blossom cups of both pineapple varieties in which the pathogens were easily penetrated into the fruit tissue after flowering. It was revealed that the fruit anatomy coupled with X-ray imaging analysis satisfied the characteristic of lignin deposition in the resistance against fungi as well as fruitlet core rot.

\subsection{Spectroscopy-based approaches}

Spectroscopy-based techniques involved in the interaction of the electromagnetic spectrum and material based on the wavelength region along with the radiation energy (Ali et al., 2019). These approaches are well known for the wide-ranging applications and disciplines, mainly in the non-destructive area. The spectroscopic-based approaches covered in this section focused on the applications for quality evaluation of pineapple. Di Egidio et al. (2009) explored the application of Fouriertransform near-infrared (FT-NIR) spectroscopy to evaluate the freshness of fresh-cut pineapple stored at three different temperatures. Principal component analysis (PCA) was used to monitor the molecular modifications over the time of the initial loss of freshness for each temperature. The findings demonstrated that NIR spectroscopy is efficient in monitoring the shelf life and freshness of pineapple which is vital for the quality assessment related to the postharvest storage. Chia et al. (2012) reported the potential of visible and shortwave nearinfrared (VIS-SWNIR) spectroscopy for the assessment of soluble solids content of pineapple. Artificial neural network was applied in the prediction of soluble solids content with the correlation coefficient of 0.86 , indicating the promising application for the non-destructive assessment of pineapple quality.
In addition, Sukwanit \& Teerachaichayut (2013) investigated the internal browning disorder of pineapple using NIR spectroscopy. Partial least squares-discriminant analysis was used to develop the prediction model with the overall classification accuracy of $90 \%$ in order to classify between sound and internally-browned pineapples. In a similar approach, Rahim et al. (2014) reported the establishment of prediction models using NIR spectroscopy treated with the second-order Savitzky-Golay derivative for the evaluation of soluble solids content in pineapple. Srivichien et al. (2015) utilized visible and near-infrared (VIS-NIR) spectroscopy to identify the nitrate level in canned pineapple for the detection of black stains on the fruit surface. Figure 2 shows the illustration of the measurement setup of VIS-NIR spectroscopy in order to evaluate the nitrate level of pineapple. The prediction model based on the nitrate contents achieved a high correlation coefficient of 0.95 which showed that VIS-NIR spectroscopy is feasible for fast screening of intact pineapple.

Another factor concerning the spectroscopic-based approaches lies in the impedance interferences from the quality changes of the sample. Conesa et al. (2015) reported the application of electrochemical impedance spectroscopy in the quantification of sugars for bioethanol production from the pineapple waste. In this work, different concentrations of glucose, fructose, and sucrose were mixed with the pineapple waste to study the respective combinations for development of prediction model using an artificial neural network with the classification rate of $93 \%$. Santos et al. (2019) described the potential of FT-IR spectroscopy to evaluate the heat treatment on the bioactivity of pineapple by-products. The pineapple byproducts were treated at three different temperatures $\left(30^{\circ} \mathrm{C}, 40\right.$ ${ }^{\circ} \mathrm{C}$, and $50{ }^{\circ} \mathrm{C}$ ) for 24 hours for the determination for total phenolic content and antioxidant capacity. The samples were distinguished according to the bioactivity using the PCA model with the spectra collected from the FT-IR spectroscopy. Amuah et al. (2019) discussed the application of NIR spectroscopy to evaluate total soluble solids for organic and inorganic pineapples. Multivariate algorithm models were established using PCA and LDA classifiers to accurately distinguished between organic and inorganic pineapples with the classification rate of $100 \%$. From this finding, it was noted that NIR spectroscopy coupled with multivariate algorithms could be exploited for rapid determination of fruit quality as well as identification for organic and inorganic fruits.

\subsection{Other non-destructive approaches}

Other non-destructive approaches for quality evaluation of pineapples are discussed in this section. Valente et al. (2001) used an acoustic impulse method to evaluate the firmness of pineapple at different maturity levels. The pineapple firmness was assessed in terms of resonant frequency and elasticity of the fruit. Based on the findings, it was found that the resonant frequency declined from 421 to $326 \mathrm{~Hz}$ whereas the elasticity obtained the correlation coefficient of 0.91 . Both parameters were promising to determine the acoustic measurement of pineapple firmness in relation to different maturity levels. In another approach, Torri et al. (2010) reported the feasibility of an electronic nose for monitoring the freshness of minimally processed pineapples stored at three different temperatures during 10 days of storage period. The results demonstrated that the electronic nose was able to classify between the pineapple samples stored at different temperatures using volatile compounds correlated with the changes of physicochemical properties of the fruit. Chaumpluk et al. (2012) investigated the maturity of pineapple using expression patterns of putative hexose transporter gene biosensor as an indicator for fruit maturity. Based on the signal detection from via biosensor, the presence of targeted color platform varied due to the presence 


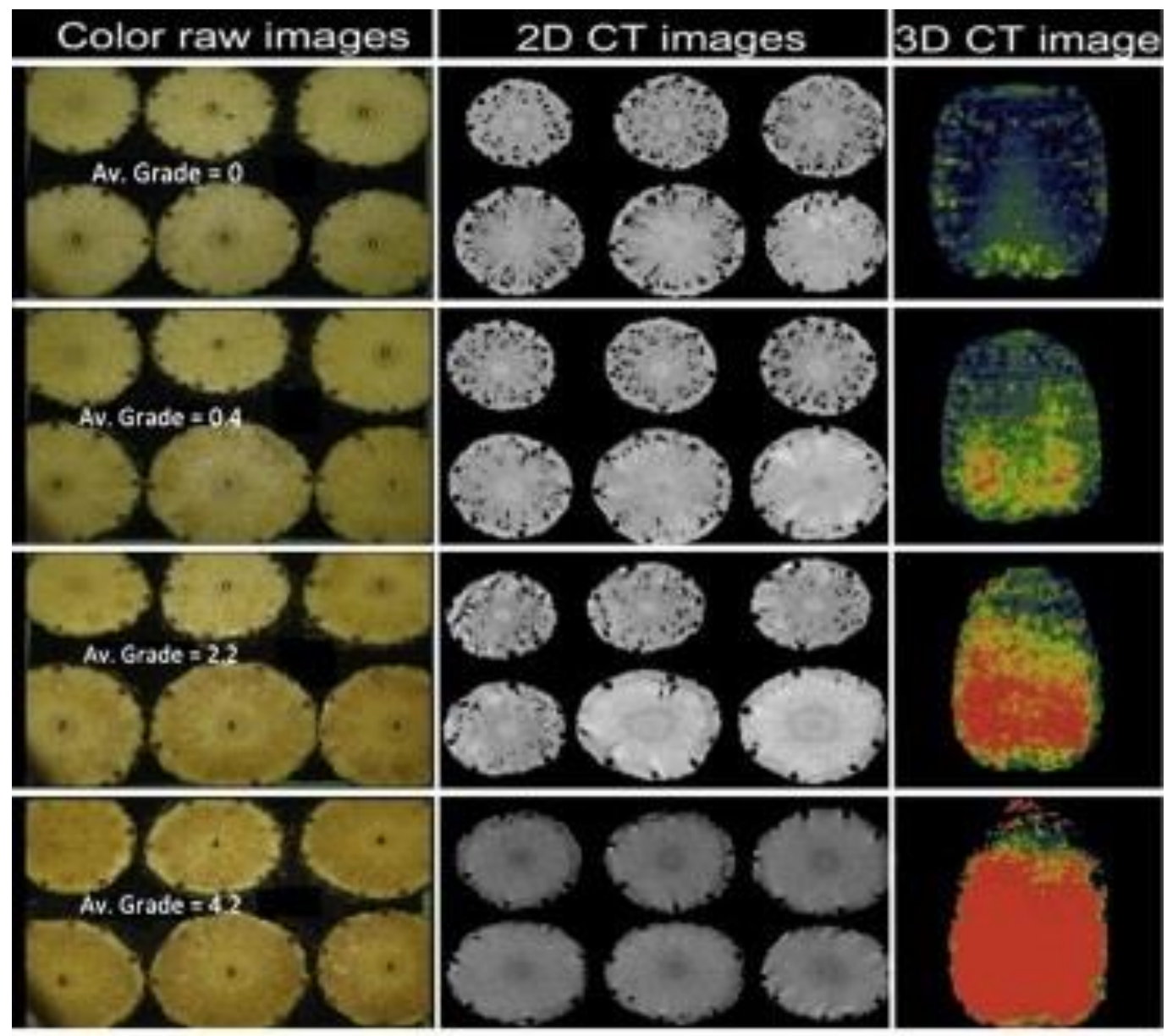

Figure 1. Color raw image slices, cross-sectional 2D CT images, and 3D reconstruction of pineapples (Donis-González et al., 2014)

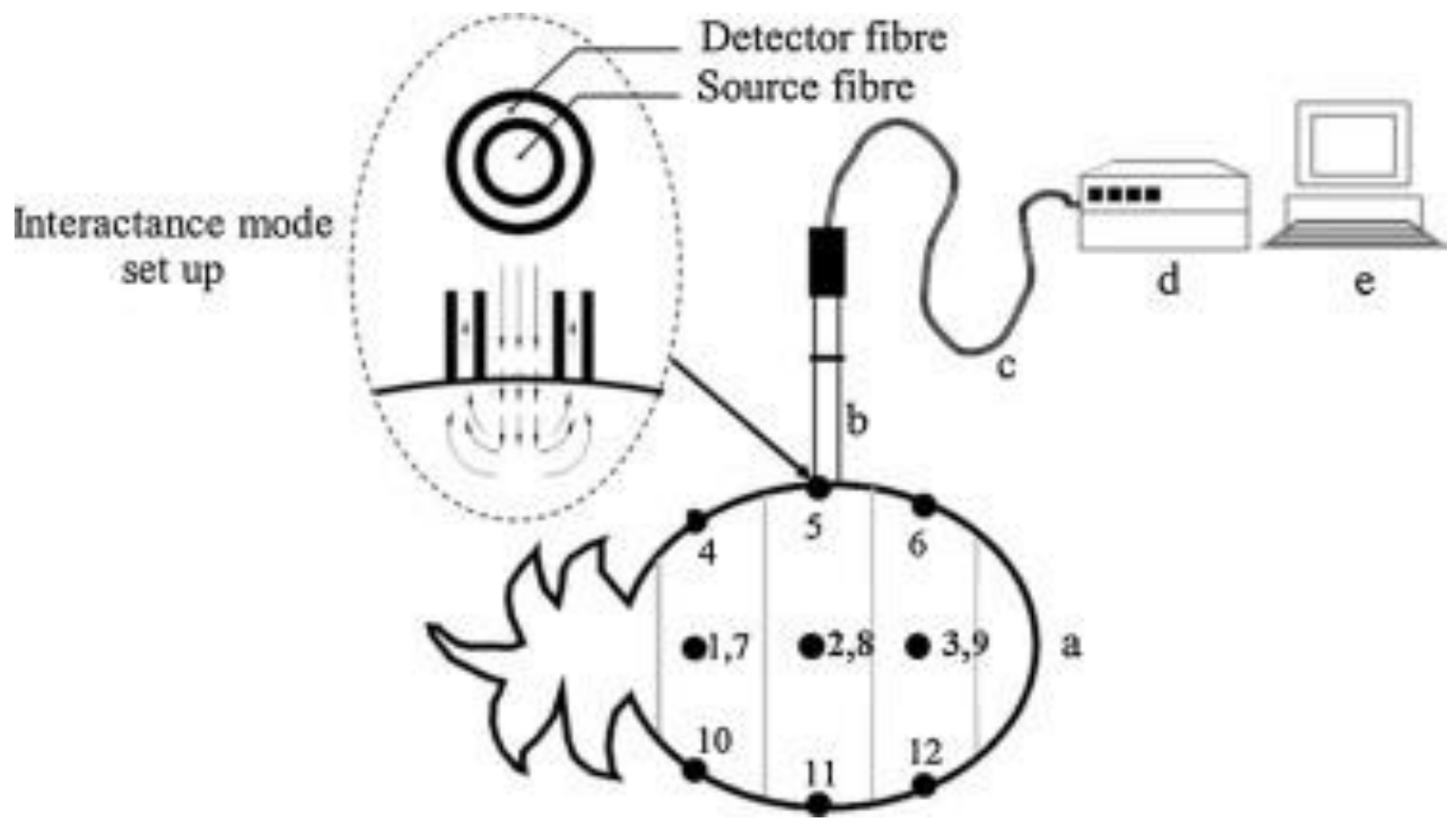

Figure 2. The schematic diagram of measurement setup: (a) pineapple (positions 1-12 are the scanned locations); (b) measurement probe; (c) fiber optic cable; (d) Vis-NIR spectrophotometer; and (e) computer (Srivichien et al., 2015) 
of gold colloid nanoparticles to determine fruit quality nondestructively.

Haddi et al. (2014) combined the application of electronic nose and electronic tongue into a multisensor data fusion in determining the aroma compounds of pineapple juices. The samples were tested using the electronic nose and electronic tongue separately as well as combining the two methods into a data fusion approach. The results achieved $100 \%$ success rate with the combination between the two methods as compared to the individual technique. Thus, performing in a multimode manner would have a promising result by offering comprehensive information in assessing safety and quality changes of fruits and vegetables. Moreover, Jam \& Chia (2017) classified the internal quality based on total soluble content, $\mathrm{pH}$, and acidity of pineapple using near-infrared light. Artificial neural network models were established to classify the internal quality of the fruit, achieving more than $70 \%$ classification accuracy for total soluble content, $\mathrm{pH}$, and acidity, respectively. Kalpana \& Lakshmi Baghyam (2019) developed an electronic nose system in order to identify the freshness and odor of pineapples using K-nearest neighbor algorithm. Based on the different odors, the pineapple samples were successfully classified according to the freshness of the fruit.

\section{Future trends}

Research studies presented in this review indicated that non-destructive approaches are well-suited for various applications such as classification, quality detection, and prediction of chemical attributes in pineapples. Computer vision, imaging-based approaches, as well as spectroscopybased approaches have been successfully utilized in replacing the conventional methods in which the bulk production in terms of quality detection and classification of pineapple varieties is required. The non-destructive approaches allow the execution of pineapple characterization in a short period compared to the analytical methods which are quite lengthy and laborious. Considering the fact that multivariate algorithms were used in the non-destructive applications, further research is needed to obtain the useful information for complex applications in monitoring quality determination of pineapples. In this sense, the efficiency of rapid determination of non-destructive approaches will be beneficial for producers in order to provide economic benefits by delivering good-quality of fruits to the consumers.

However, the technology transfer of these non-destructive approaches from laboratory scale to industrial scale will require some extensions, especially in the particular needs in the pineapple market so that it can be determined in the field scale. The commercial utilization of the non-destructive approaches, either individually or coupled with multivariate algorithms indicated that the ability of these techniques to reduce the defects or damages in the quality determination of the fruit. Apart from that, it is recommended that the development of a portable or handheld device is suitable to determine the quality attributes of pineapples during storage as well as estimate the optimal harvest time of the fruit. The variation of varieties, sizes and shapes of pineapples also need to be addressed for nondestructive applications, particularly after harvesting and during postharvest storage. The research works on evaluating internal chemical composition of pineapples is growing tremendously with the recent advances on suitable multivariate algorithms including artificial neural network (ANN), support vector machine (SVM), partial least squares (PLS), and principal component analysis (PCA) which is important to create a possible commercial system in the near future.

\section{Conclusions}

The pineapple industry has huge potential for technological advancement in the domestic and international commercial line. This review has covered recent applications of non-destructive techniques for pineapple quality evaluation. In addition to the goal of the pineapple industry of delivering good quality fruits, the non-destructive approaches have demonstrated the potential and importance of those applications to provide new knowledge. The main benefit of utilizing these techniques is mostly in terms of chemical-free evaluation method in which no sample preparation is required for the whole process compared to the conventional technique. The wide range applications of non-destructive approaches offer numerous potential advantages including reduced labor costs, time-saving, and increased the robustness of real-time operations. Nevertheless, it is beneficial for the researchers to transfer the knowledge from the laboratory scale to industrial scale in order to enable early sorting of the fruit with minimal losses and additional analytical methods. Thus, it is anticipated that the nondestructive approaches would progressively become a routine analysis for quality determination of pineapples as well as other agricultural produce.

\section{Declaration of competing interest}

The authors have declared no conflict of interest.

\section{Author contributions}

Maimunah Mohd Ali edited and drafted the manuscript. Norhashila Hashim critically revised and finalized the manuscript. Samsuzana Abd Aziz and Ola Lasekan provided advice in the manuscript revisions.

\section{Acknowledgements}

The authors wish to acknowledge the technical support provided by the Department of Biological and Agricultural Engineering, Faculty of Engineering and Department of Food Technology, Faculty of Food Science and Technology, Universiti Putra Malaysia.

\section{References}

Abu Bakar, B. H., Ishak, A. J., Shamsuddin, R., \& Wan Hassan, W. Z. (2013). Ripeness level classification for pineapple using RGB and HSI colour maps. Journal of Theoretical and Applied Information Technology, 57(3), 587-593.

Ali, M. M., Bachik, N. A., Muhadi, N. 'Atirah, Tuan Yusof, T. N., \& Gomes, C. (2019). Non-destructive techniques of detecting plant diseases: A review. Physiological and Molecular Plant Pathology, 108, 1-12. https://doi.org/10.1016/j.pmpp.2019.101426

Amuah, C. L. Y., Teye, E., Lamptey, F. P., Nyandey, K., OpokuAnsah, J., \& Adueming, P. O. W. (2019). Feasibility Study of the Use of Handheld NIR Spectrometer for Simultaneous Authentication and Quantification of Quality Parameters in Intact Pineapple Fruits. Journal of Spectroscopy, 2019, 1-10. https://doi.org/10.1155/2019/5975461

Angel, L., Lizcano, S., \& Viola, J. (2015). Assessing the state of maturation of the pineapple in its perolera variety using computer vision techniques. 20th Symposium on Signal Processing, Images and Computer Vision, 1-6. https://doi.org/10.1109/STSIVA.2015.7330446

Barral, B., Chillet, M., Léchaudel, M., Lartaud, M., Verdeil, J. L., Conéjéro, G., \& Schorr-Galindo, S. (2019). An Imaging Approach to Identify Mechanisms of Resistance to Pineapple Fruitlet Core Rot. Frontiers in Plant Science, 10, 
1-12. https://doi.org/10.3389/fpls.2019.01065

Brosnan, T., \& Sun, D. W. (2004). Improving quality inspection of food products by computer vision - A review. Journal of Food Engineering, 61, 3-16.

Bugaud, C., \& Alter, P. (2016). Volatile and non-volatile compounds as odour and aroma predictors in dessert banana (Musa spp.). Postharvest Biology and Technology, $112,14-23$.

Chaumpluk, P., Chaiprasart, P., \& Vilaivan, T. (2012). Postharvest non-destructive determination of fruits: A model on fruit maturity assay via biosensor based on colorimetric change of gold nanoparticles. Acta Horticulturae, 945, 205-212.

Chia, K. S., Abdul Rahim, H., \& Abdul Rahim, R. (2012). Prediction of soluble solids content of pineapple via non-invasive low cost visible and shortwave near infrared spectroscopy and artificial neural network. Biosystems Engineering, 113(2), 158-165.

Conesa, C., García-Breijo, E., Loeff, E., Seguí, L., Fito, P., \& Laguarda-Miró, N. (2015). An electrochemical impedance spectroscopy-based technique to identify and quantify fermentable sugars in pineapple waste valorization for bioethanol production. Sensors (Switzerland), 15(9), 22941-22955. https://doi.org/10.3390/s150922941

Di Egidio, V., Sinelli, N., Limbo, S., Torri, L., Franzetti, L., \& Casiraghi, E. (2009). Evaluation of shelf-life of fresh-cut pineapple using FT-NIR and FT-IR spectroscopy. Postharvest Biology and Technology, 54(2), 87-92. https://doi.org/10.1016/j.postharvbio.2009.06.006

Dittakan, K., Theera-Ampornpunt, N., \& Boodliam, P. (2018). Non-destructive Grading of Pattavia Pineapple using Texture Analysis. International Symposium on Wireless Personal Multimedia Communications, 144-149. https://doi.org/10.1109/WPMC.2018.8713088

Donis-González, I. R., Guyer, D. E., Pease, A., \& Barthel, F. (2014). Internal characterisation of fresh agricultural products using traditional and ultrafast electron beam X-ray computed tomography imaging. Biosystems Engineering, 117(1), 104-113.

Haddi, Z., Mabrouk, S., Bougrini, M., Tahri, K., Sghaier, K., Barhoumi, H., El Bari, N., Maaref, A., Jaffrezic-Renault, N., \& Bouchikhi, B. (2014). E-Nose and e-Tongue combination for improved recognition of fruit juice samples. Food Chemistry, 150, 246-253.

Haff, R. P., Slaughter, D. C., Sarig, Y., \& Kader, A. (2006). X-ray assessment of translucency in pineapple. Journal of Food Processing and Preservation, 30(5), 527-533.

Jam, M. N. H., \& Chia, K. S. (2017). A five band near-infrared portable sensor in nondestructively predicting the internal quality of pineapples. EEE 13th International Colloquium on Signal Processing and Its Applications, CSPA 2017, 135-138.

Kaewapichai, W., Kaewtrakulpong, P., Prateepasen, A., \& Khongkraphan, K. (2007). Fitting a Pineapple Model for Automatic Maturity Grading. IEEE International Conference on Image Processing, 257-260.

Kalpana, S., \& Lakshmi Baghyam, A. (2019). Electronic-nose system for classification of fruits and freshness measurement using K-NN algorithm. International Journal of Innovative Technology and Exploring Engineering, 8(6S4), 641-644.

Khatiwada, B. P., Walsh, K. B., \& Subedi, P. P. (2016). Internal defect detection in fruit by using NIR Spectroscopy. Acta Horticulturae, 1120, 337-342.

Li, Bin, Wang, M., \& Li, L. (2010). A real-time pineapple matching system based on speeded-up robust features. International Conference on Computational Intelligence and Security, 243-247.

Li, Bin, Wang, M., \& Wang, N. (2010). Development of a real-time fruit recognition system for pineapple harvesting robots. American Society of Agricultural and Biological Engineers Annual International Meeting 2010, 6(10), 4958-4968. https://doi.org/10.13031/2013.29922

Li, Bo, Lecourt, J., \& Bishop, G. (2018). Advances in nondestructive early assessment of fruit ripeness towards defining optimal time of harvest and yield prediction-a review. Plants, 7(1), 1-20.

Lima, R. P., Silva, S. M., Dantas, R. L., Dantas, A. L., Sousa, A. S. B., Pereira, W. E., Mendonça, R. M. N., \& Guimarães, G. H. C. (2016). Using digital image processing for evaluation of translucency in fresh-cut "Pérola" pineapple coated with biofilms. Acta Horticulturae, 1141, 311-318. https://doi.org/10.17660/ActaHortic.2016.1141.39

Mohammad, S., Ghazali, K. H., Zan, N. C., Radzi, S. S. M., \& Karim, R. A. (2012). Classification of fresh N36 pineapple crop using image processing technique. Advanced Materials Research, 418-420, 1739-1743.

Mohd Ali, M., Hashim, N., Bejo, S. K., \& Shamsudin, R. (2017) Rapid and nondestructive techniques for internal and external quality evaluation of watermelons: A review. Scientia Horticulturae, 225, 689-699. https://doi.org/10.1016/j.scienta.2017.08.012

Nawawi, M. A. A., \& Ismail, F. S. (2017). Simulation and Segmentation Techniques for Crop Maturity Identification of Pineapple Fruit. Modeling, Design and Simulation of Systems. In Asian Simulation Conference., 752, 3-11. https://doi.org/10.1007/978-981-10-6463-0

Phoophuangpairoj, R., \& Srikun, N. (2014). Computerized recognition of pineapple grades using physicochemical properties and flicking sounds. International Journal of Agricultural and Biological Engineering, 7(3), 93-101. https://doi.org/10.3965/j.ijabe.20140703.011

Rahim, H. A., Seng, C. K., \& Rahim, R. A. (2014). Analysis for soluble solid contents in pineapples using NIR spectroscopy. Jurnal Teknologi (Sciences and Engineering), 69(8), 7-11.

Santos, D. I., Correia, M. J. N., Mateus, M. M., Saraiva, J. A., Vicente, A. A., \& Moldão, M. (2019). Fourier transform infrared (FT-IR) spectroscopy as a possible rapid tool to evaluate abiotic stress effects on pineapple by-products. Applied Sciences, 9(19), 1-11.

Shamsudin, R., Daud, W. R. W., Takriff, M. S., \& Hassan, O. (2007). Physicochemical properties of the Josapine variety of pineapple fruit. International Journal of Food Engineering, 3(5), 1-12. https://doi.org/10.2202/1556-3758.1115

Siti Rashima, R., Maizura, M., Wan Nur Hafzan, W. M., \& Hazzeman, H. (2019). Physicochemical properties and sensory acceptability of pineapples of different varieties and stages of maturity. Food Research, 3(5), 491-500. https://doi.org/10.26656/fr.2017.3(5).060

Sornsrivichai, J., Yantarasri, T., \& Kalayanamitra, K. (2000). Nondestructive techniques for quality evaluation of pineapple fruits. Acta Horticulturae, 529, 337-341. https://doi.org/10.17660/ActaHortic.2000.529.40

Srivichien, S., Terdwongworakul, A., \& Teerachaichayut, S. (2015). Quantitative prediction of nitrate level in intact pineapple using Vis-NIRS. Journal of Food Engineering, 150, 29-34.

Suksawat, B., \& Komkum, P. (2015). Pineapple quality grading using image processing and fuzzy logic based on Thai Agriculture Standards. International Conference on Control, Automation and Robotics, 218-222. https://doi.org/10.1109/ICCAR.2015.7166035

Sukwanit, S., \& Teerachaichayut, S. (2013). Nondestructive prediction of internal browning in pineapple using transmittance short wavelength near infrared spectroscopy. Acta Horticulturae, 989, 395-400. https://doi.org/10.17660/actahortic.2013.989.54 
Sung, J., Suh, J. H., Chambers, A. H., Crane, J., \& Wang, Y. (2019). Relationship between Sensory Attributes and Chemical Composition of Different Mango Cultivars [Researcharticle]. Journal of Agricultural and Food Chemistry, 67(18), 5177-5188.

Torri, L., Sinelli, N., \& Limbo, S. (2010). Shelf life evaluation of fresh-cut pineapple by using an electronic nose. Postharvest Biology and Technology, 56(3), 239-245. https://doi.org/10.1016/j.postharvbio.2010.01.012

Valente, M., Duprat, F., Grotte, M., \& Lasaygues, P. (2001). Nondestructive evaluation of firmness of fresh pineapple by acoustic method. Acta Horticulturae, 562, 391-396. https://doi.org/10.17660/ActaHortic.2001.562.46

Yee, P. M., Shamsudin, R., Hamzah, A., \& Endan, E. (2011). Kinetic studies on cooking of pineapple bakery jam. American Journal of Food Technology, 6(7), 594-603. https://doi.org/10.3923/ajft.2011.594.603 